\title{
Redeployment: a new paradigm for ophthalmology professionals
}

\author{
Michelle S. Attzs $\mathbb{D}^{1} \cdot$ Bansri K. Lakhani ${ }^{1}$
}

Received: 4 April 2020 / Revised: 17 April 2020 / Accepted: 17 April 2020 / Published online: 28 April 2020

(c) The Royal College of Ophthalmologists 2020

\section{To the Editor:}

As the world is plunged into new and uncertain times, 'redeployment' is emerging as the novel word in the lexicon of ophthalmologists. At the end of 2019, the World Health Organization was notified by health officials in the Chinese province of Hubei, about the presentation of pneumonia of unknown aetiology. Subsequent biological and genomic testing revealed a new type of coronavirus, which we now know as COVID-19 [1]. Following the discovery of the first case, there has been an exponential rise in those infected, and as of 3 April 2020, there have been $1,088,878$ confirmed cases of COVID-19, with a total of 58,382 deaths [2].

In our response to this pandemic, Ophthalmology in the United Kingdom (U.K.) has seen a dramatic change in its operations. The Royal College of Ophthalmologists (RCOphth) has produced guidance on how ophthalmic services in the U.K. should endure the current crisis [3], in line with a directive from NHS England and NHS Improvement to postpone all non-urgent outpatient and surgical workload [4]. The RCOphth website offers guidance on the risk stratification of patients to ensure that none suffer permanent sight loss as a result of the delay to their appointment or treatment, whilst protecting both staff and patients by reducing the departmental footfall [5].

The dramatic decrease in clinical and surgical activity in Ophthalmology departments across the U.K. has resulted in the redeployment of Ophthalmology doctors to alternative, frontline hospital environments to assist with the COVID19 response. Redeployment may be a known concept within the NHS, but it is certainly new to the vocabulary of the Ophthalmology departments. Never, in its 70-year history,

Michelle S. Attzs

michelle.attzs@gmail.com

1 Department of Ophthalmology, Nottingham University Hospitals NHS Trust, Derby Rd, Nottingham NG7 2UH, UK has the NHS encountered the need to implement such widespread, safe restructuring of its workforce [6].

The local unit of the authors of this article has begun a staged process, with the most junior trainees being redeployed to acute wards as part of a mega SHO rota between ENT, Maxillofacial and Neurosurgery. In preparation for what seems like the inevitable, senior registrars and consultants have started a process of staged shadowing and simulation training, in order to prepare for the time when they are required in these different hospital environments. Whilst this is occurring, the ophthalmic service is operating at around $20 \%$ with emergency eye care provision still paramount.

The redeployment of Ophthalmology doctors gives rise to many questions. As doctors, what level of basic medical knowledge and skills should we retain throughout our training? Should all levels of Ophthalmology doctors be redeployed? How will we cope with the unfamiliar working patterns, unknown teams and new bosses, especially given the current climate of crisis?

The key messages from the General Medical Council [7], the four Statutory Education Bodies [8] and Academy of Medical Royal Colleges [9] are consistent; advice must always be sought when working in an unfamiliar environment, work within your competence, and most importantly, remember no one is alone in this new journey of redeployment and that everyone has the same anxieties and concerns [10].

\section{Compliance with ethical standards}

Conflict of interest The authors declare that they have no conflict of interest.

Publisher's note Springer Nature remains neutral with regard to jurisdictional claims in published maps and institutional affiliations.

\section{References}

1. World Health Organization. Novel Coronavirus (2019-nCoV) situation report 1. Geneva: World Health Organization; 2020. 
https://www.who.int/docs/default-source/coronaviruse/situationreports/20200121-sitrep-1-2019-ncov.pdf?sfvrsn=20a99c10_4.

2. John Hopkins Coronavirus Resource Center. COVID-19 Map. Baltimore: John Hopkins Coronavirus Resource Center; 2020. https://coronavirus.jhu.edu/map.html.

3. Royal College of Ophthalmologists. RCOphth. Management of Ophthalmology Services during the Covid pandemic. London: Royal College of Ophthalmologists; 2020. https://www.rcophth.ac. uk/wp-content/uploads/2020/03/RCOphth-Management-of-Ophtha lmology-Services-during-the-Covid-pandemic-280320.pdf.

4. Stevens S, Pritchard A. Next steps on NHS response to COVID-19. London: NHS England and NHS Improvement; 2020. https://www.england.nhs.uk/coronavirus/wp-content/uploads/ sites/52/2020/03/20200317-NHS-COVID-letter-FINAL.pdf.

5. Moorfields Eye Hospital NHS Foundation Trust. Moorfields Ophthalmic risk stratification implementation guideline version 2. London: Moorfields Eye Hospital NHS Foundation Trust; 2020. https://www.rcophth.ac.uk/wp-content/uploads/2020/03/ Moorfields-Ophthalmic-Risk-Stratification-ImplementationGuideline-V2.0.pdf.
6. NHS England. Redeploying your secondary care medical workforce safely. London: NHS England; 2020. https://www.england. nhs.uk/coronavirus/publication/redeploying-your-secondary-caremedical-workforce-safely/.

7. General Medical Council. Joint statement: supporting doctors in the event of a Covid-19 epidemic in the UK. London: General Medical Council; 2020. https://www.gmc-uk.org/news/news-a rchive/supporting-doctors-in-the-event-of-a-covid19-epidemic-inthe-uk.

8. Mangat P, Gardiner K, Parks R, MacLeod S, Melville C. Supporting the COVID-19 response: guidance regarding Medical Education and Training. Leeds; Health Education England; 2020. https://www.hee.nhs.uk/sites/default/files/documents/Supporting \%20the\%20COVID-19\%20Response.pdf.

9. Academy of Medical Royal Colleges. Deployment of staff during the COVID-19 pandemic. London: Academy of Medical Royal Colleges; 2020. https://www.aomrc.org.uk/wp-content/uploads/ 2020/03/270320_deployment_during_COVID-19.pdf.

10. Rimmer A. How can I cope with redeployment? BMJ. 2020;368: m1228. https://www.bmj.com/content/bmj/368/bmj.m1228.full.pdf. 